Das deutsche Drama von Gottsched bis Lessing 


\section{Das deutsche Drama von Gottsched bis Lessing}

Ein historischer Überblick

J.B. Metzlersche Verlagsbuchhandlung Stuttgart 
CIP-Kurztitelaufnahme der Deutschen Bibliothek

Steinmetz, Horst:

Das deutsche Drama von Gottsched bis Lessing:

e. histor. Uberblick / Horst Steinmetz. -

Stuttgart: Metzler, 1987.

ISBN 978-3-476-00625-7

ISBN 978-3-476-00625-7

ISBN 978-3-476-03250-8 (eBook)

DOI 10.1007/978-3-476-03250-8

Dieses Werk einschließlich aller seiner Teile ist urheberrechtlich geschützt. Jede Verwertung außerhalb der engen Grenzen des Urheberrechtsgesetzes ist ohne Zustimmung des Verlages unzulässig und strafbar. Das gilt insbesondere für Vervielfältigungen, Ubersetzungen, Mikroverfilmungen und die Einspeicherung und Verarbeitung in elektronischen Systemen.

C 1987 Springer-Verlag GmbH Deutschland

Ursprünglich erschienen bei J. B. Metzlersche Verlagsbuchhandlung und Carl Ernst Poeschel Verlag GmbH in Stuttgart 1987 


\section{Inhalt}

\section{Vorwort VII}

\section{Einleitung 1}

Literaturgeschichte und Sozialgeschichte 1

Grundzüge des Dramas und seiner Entwicklung im 18. Jahrhundert 8

Die Zeit von 1680 bis 173016

Allgemeine Kennzeichen von Drama und Theater um 170016

Die Oper 19

Christian Weise 23

Die Situation vor Gottsched 27

Die Begründung des "regelmäßigen « Dramas als eines praktischen Instruments gesellschaftlicher Aufklärung und Erziehung in der Gottschedzeit 31

Gottscheds Konzeption des Dramas 31

Die Deutsche Schaubübne als literarische Umsetzung gesellschaftlich-bürgerlicher Erziehungsideale 42

Die Exemplifizierung eines rationalen Weltbildes in der Tragödie 42

Die satirische Typenkomödie als gesellschaftliches Regulativ 49

Vollendung und Modifizierung des Gottschedischen

Dramenmodells bei J. E. Schlegel und Lessing 54

Implizite Gesellschaftskritik und individuelle Auflehnung in J. E. Schlegels Canut 54

Konsequente gesellschaftliche Aufklärung in Lessings Der Freygeist und Die Juden 58

Das bürgerliche Drama. Entstehung und Anspruch ideologisch-resignativer Selbstdarstellung des Bürgers 62

Empfindsame Selbstvergewisserung im rührenden Lustspiel 62 Mißglückter gesellschaftlicher Anspruch im bürgerlichen Trauerspiel 70 
Widersprüche und Ungleichzeitigkeiten.

Dramaturgische Theorie und Praxis des Dramas

in der Mitte des Jahrhunderts 83

Mitleid und Menschlichkeit als theoretische Grundlagen

eines bürgerlich-unständischen Dramas 83

Tradition und Traditionsveränderung 88

Die Erfahrung von Subjektivismus und Leiden im klassizistischen und experimentellen Drama 88

Christian Felix Weißes Tragödien: Beispiele gegenläufiger Entwicklungen 103

Im Widerspruch von Sozial- und Literaturgeschichte:

Das Hamburger Nationaltheater 108

Lessings Drama als Vollendung und Kritik aufklärerischer

Denk-, Sozial- und Dramenstrukturen 119

Anmerkungen 130

Literaturhinweise 134

Register 138 


\section{Vorwort}

Historische Úberblicke sind - obwohl das Wort "historisch “ Objektivität suggeriert - subjektive Darstellungen von Geschichte oder von Kapiteln aus der Geschichte. Bereits die Tatsache, daß sie an bestimmter Stelle in der Geschichte beginnen und enden, ist Ausdruck dieser Subjektivität, die für die Gliederung in Perioden und Phasen verantwortlich ist. Kein Autor geschichtlicher Darstellungen wird hieb- und stichfest begründen können, warum er seinen Úberblick an den gewählten und keinen anderen Zeitpunkten beginnen oder enden läßt.

Auch der Autor der vorliegenden Darstellung kann dies nicht. Andere Einteilungen und Gliederungen des Dramas des 18. Jahrhunderts sind denkbar und möglich. Auch sie aber werden - nicht anders als der hier veröffentlichte Vorschlag - ihre Plausibilität nicht mit vorgegebener historischer Faktizität legitimieren können, sondern nur mit der explizit oder implizit angewandten (subjektiven) Deutung der Geschichte dieses Dramas.

Allerdings kam es mir auch nicht in erster Linie auf eine Periodengewichtung an. Mir ging es primär um eine Darstellung des historischen Zusammenhanges und der historischen Entwicklung innerhalb eines bestimmten Zeitraumes. Darum zum Beispiel der so gut wie vollständige Verzicht auf biographische Daten, darum die Lösung der Werke aus dem jeweiligen Gesamtoeuvre der Autoren. Als "historisch " aber habe ich auch die Verpflichtung verstanden, nicht nur auf bestimmte, heute im allgemeinen als fortschrittlich angesehene Dramen einzugehen, wie das bürgerliche Trauerspiel, sondern auch andere, heute praktisch negierte Typen und Formen einzubeziehen, wie die heroische Tragödie. Nur so schien mir eine approximativ adäquate Wiedergabe der historischen Wirklichkeit möglich.

Historischer Uberblick kann nicht heißen, daß die Darstellung konsequent der Chronologie folgt. Weil ein historischer Úberblick subjektive Deutung von Geschichte involviert, die Einblick in dasjenige verschaffen will, was als Verlauf und Struktur des Vergangenen erkannt wird, ordnet auch der hier vorgelegte Úberblick sein Material in Kapitel und Blöcke, die im ganzen zwar der Chronologie folgen, aber doch durch anderes als nur die Chronologie fundiert sind. Das hat unter anderem zur Folge, daß Lessings Dramen mehr als einmal und an verschiedenen Stellen diskutiert werden. - Daß schließlich die gesamte Darstellung auf die rekurrente Frage- 
und Themenstellung des gesellschaftlichen Appells des Dramas aus der Aufklärung ausgerichtet ist, hat seine Ursache ebenfalls im Prinzip der Deutung, das jeder historische Überblick verlangt und voraussetzt.

Leiden, im März 1987

H. S. 